the limb or limbs in which analgesia was so profound that strong faradism did not make the child wince, some other parts of the body showed a lack of ordinary response. It is difficult to believe that in such cases there can be the elements of expectant attention or of auto- or hetero-suggestion. It is easier to believe that in the state called hysteria there is a general alteration of the nervous system, and in some of the shock cases either a blood or a secretory gland change.

$$
\text { Conclusion. }
$$

In conclusion, the above remarks are meant to apply only to genuine cases of the neuroses. The difficulty in discriminating between malingering and a true neurosis is very great, and, as Buzzard ${ }^{6}$ says in his remarks on the diagnosis, we are very apt to be biased by our personal feeling towards the patient. He gives an amusing instance of this: a patient suffering from mutism was such a nice fellow that no one would call him anything but a case of hysteria, but his only successful attempt to speak was when he blurted out that he would iather be dumb for the rest of his life than go back to the front. True malingering-that is, conscious simulation-is rare. It is, however, often combined with true hysteria, or unconscious simulation, and it is such combinations that I think lend themselves most readily to dramatic cures.

I have dealt with the underlying physical basis of the neuroses, because there seems to be a tendency to lay undue stress on the psychical factor. At any rate, it seems likely that molecular disturbances of the nervous system and altered blood states largely account for the long duration of many cases and for the great tendency for symptoms to relapse on the slightest provocation, whether that be undue exertion, loud sudden noises, or family or business anxieties.

In the most common type of case I believe that better results will be attained by fresh air, sunlight, cheerful surroundings, and light work. than by continuous searching for a hidden mental conflict. Of the value of psycho-analysis in certain intractable cases where there are reasons for suspecting a repressed memory or complex, I am not competent to express an opinion. Nor am I tempted to undertake the necessary investigations when I read that a three years' study of the subject is essential, and that to unravel a complex, to trace some of its elements back, possibly to some incident in childhood, often a very muddy one, may occupy the constant attention of the psycho-analyst for at least several months, and sometimes for a year and even longer.

References.-1. Wilson, S. A. Kinnier, and Walshe, F. M. R. : Brain, vol. xxxvii., p. 199. 2. Holmes, Gordon : Brain, vol. xx vii., p. 327. ' 3 Wilson, s. A. Kinnier : Brain, vol. xxxiv., p. 295, and vol. xxxvi., p. 427. 4, Orr, David, and Rows, R. G.: Brain, vol. xli., p. Buzzard, Farquhar: Proc. Royal Society of Medicine, Neurological Section, 1915, p. 65 .

\section{THE INFLUENCE OF SUGGESTION ON BODY TEMPERATURE.}

BY J. A. HADFIELD, M.A. Oxon., M.B., CH.B.Edin.

MoRe than two years ago I published in this journal ${ }^{1}$ \& paper describing experiments in which blisters were produced by hypnotic suggestion. Since that time I have made the same attempt in perhaps half a dozen cases without success. But I have recently had under observation another case of the same kind in which a blister was formed even more rapidly than in my previous case. I do not propose to describe this experiment, for it was not dissimilar to the last. This case, however, showed a very remarkable susceptibility to suggestions of heat and cold, which was not purely subjective, but produced a rise and fall of temperature as measured by the thermometer. The temperature of both hands was taken with the bulb of the thermometer held firmly in the middle of the palm, and found to be-right, $89^{\circ} \mathrm{F}$.; left, $90^{\circ} \mathrm{F}$. Then suggestions of "cold" were made relative to the left arm. Subjective feelings of cold were

1 The: Lancet, 1917, ii., 678. felt immediately, but no change in temperature took place for three minutes. Then the temperature began to fall, till it reached $85^{\circ}$ in the left hand, whilst it remained at $89^{\circ}$ in the right. This change took place in the course of ten minutes, and the thermometer was still descending when suggestions of "warmth" were made, which restored the temperature to $89^{\circ}$ in the right hand.

Later in the day a much greater change of temperature was obtained by suggestion. The patient was taken out for a five-mile walk without gloves and carrying nothing, and with both hands free, in order to equalise the temperature in both hands. Suggestions were then made of "cold," this time to the right arm, for purposes of control. The arm immediately began to get chilly, subjectively and objectively. In half an hour the temperature in the left palm was $94^{\circ}$ whilst that in the right was $68^{\circ}$. It is interesting to note that this temperature $-68^{\circ}$-was the exact temperature of the room at the time, the circulation having apparently no effect on the skin temperature. The right hand appeared and felt to the touch extremely cold, and great discomfort was produced. To the touch the right hand felt like ice, whilst the left hand was comparatively warm. Leaving the thermometer still in the palm of the hand, I then suggested the right hand warm again. Almost immediately the thermometer began to rise, till at the end of 20 minutes the right hand stood at $94^{\circ}$ and the left at $95^{\circ}$.

A further remarkable incidence is that, though I have frequently hypnotised this patient, the suggestions of this experiment were made entirely in the waking condition.

Relation of Pain to Inflammation.

As already remarked, I had previously produced "suggestion" blisters in this patient, and a blister was also produced by touching the arm with'a heated thermometer case, suggesting in the latter case that there would be no pain, either at the time or afterwards. The result was as suggested; but there was no inflammation surrounding the blister, as there was surrounding the painful blister produced by suggestion. This supports the view suggested in my article of November, 1917, that it is not the inflammation primarily that produces the pain or sensation, but the pain that produces the inflammation.

This principle was generally supported by a further observation. After two days the hypnotic blister became infected by the slipping of the bandages, and produced a more extensively painful and inflamed condition. By a word of waking suggestion the pain was abolished, with the result that in two or three minutes the inflammation was also reduced, and the hyperæmia and redness nearly disappeared. It was then found possible, by suggestion of heat and pain, to restore the wound to a painful and inflamed condition once again. The suggestion of "cold" had a more marked effect than that of "painlessness" in bringing about the reduction of inflammation.

Whilst I have mentioned these experiments in particular, they were not isolated, either in this or other patients. I frequently repeated the raising and lowering of the temperature of the arm in this patient. This phenomenon was produced in other patients, not only by myself, but by Captain G. de H. Dawson and Captain O. Connell at Ashhurst Hospital. In these cases, curiously enough, we were able to raise the temperature of a hand, but could not lower the temperature by sugges. tion. It is further noted in the cases I observed that when we suggested "heat" to one hand, it was the other hand that first showed signs of rising warmth on the thermometer; and then the suggested hand would go ahead and "beat" the other, till there was a very marked difference between the two. The greatest range of temperature that I have observed is the one detailed above; but Captain Dawson claims to have produced a rise of $20^{\circ}$. This, however, was, I believe, in an arm which corresponded closely to the type known by Babinski as "reflex," with a wound and vascular" changes present.

If these conclusions of the effect of suggestion on body -and particularly cutaneous-temperature can be estab. 
lished it will surely be of great import, both to physiology as a whole and to dermatology in particular. Have not some skin diseases been known to be associated with the neurotic constitution? If the auto-suggestion of a neurotic can influence the circulation and depress the nutrition of the skin in the way that our heterosuggestion has done in these experiments the connexion becomes obvious. The experiments described above are very tentative and suggestive; there remains the more important experiment of determining whether suggestion can raise and lower the whole body temperature. My patient, Mrs. N., to whom my thanks are due for these experiments, performed at considerable discomfort to herself, has placed me under the greater obligation of offering herself for further experimentation.

\section{SUGGESTIONS FOR THE}

\section{MASS TREATHENT OF HOOKTYOR INFECTION. ${ }^{1}$}

BY DR. S. T. DARLING,

PROFESSOR OF HYGIENR, FACULDADE DE MEDICINA E CIRURGIA DE s. PAULO.

In the course of the work of the Malaya Board in the Far East some new data were obtained on hookworm infection and its treatment and on malaria, data of value to the doctor, the employer of native labour, and the administrator. The Malaya Board consisted of Dr. M. A. Barber, Dr. H. P. Hacker, and myself as chairman. It worked in Malaya, Java, and Fiji under the auspices of the British Colonial Office and the Netherland Indies Health Department, and was supported by the Rockef'eller Foundation. 'The object of its researches was to ascertain to what extent hookworm infection affected the working efficiency of the people in the countries named. Our work disclosed the fact that hookworm infection exists to a greater extent in the tropical East than is generally recognised. In most communities and districts the great bulk of the people are agriculturists. Practically 100 per cent. of adolescents and adults of this class are infected with hookworm.

It was shown very positively that there is a correspondence between the degree of infection - that is, the actual number of worms harboured-and the amount of blood loss or anæmia suffered. This loss was frequently hidden or undetectable due to abundant food, opportunities for rest, and to active hæmatopoiesis in certain resistant individuals, but the drain and loss were none the less real, and constituted a tax on the vital powers.

Working with a large number of persons from whom practically all the hookworms had been expelled by vermifuge and counted it was estimated that a given number of hookworms produced a corresponding amount of blood loss. A given number of worms produced more anæmia among children than an equal number in women, and more among women than an equal number in men. Furthermore a given number of Ankylostoma duodenale was found to produce a greater degree of anæmia than an equal number of Necator americanus, probably due to the more severe hæmorrhage caused by the former worm. Finally, it was estimated that about 12 hookworms are required to cause a loss of 1 per cent. hæmoglobin. When the number of worms harboured is considerable the anæmia. caused is evident and measurable; when but few worms are harboured the blood loss may not be detectable.

It is extremely important that emphasis be placed on this fact that hookworms are constantly causing losses of blood through multiple small worm-bites.

Observations made by the Malaya Board are of such a character that the amount of blood loss caused by hookworms and the resulting loss of efficiency can be demonstrated graphically to planters and other employers of labour. Using a rigorous method of diagnosing cases of infection by the administration of

1 This paper is based on work done in Java and Brazil, where $I$ was assisted by Dr. M. E. Barnes and Dr. W. G. Smillie, and in part on work done in Malaya and Fiji with Dr. M. A. Barber and Dr. H. P. Hacker. Certain data are extracted from our joint report to the International Health Board which will appear later. vermifuge and comparing it with the less accurate method of microscopic examination of fæces for ova it was ascertained that a larger proportion of the inhabitants of tropical countries are infected with hookworms than is generally suspected. For example, where the microscopic examination revealed in the hands of the lay microscopist an incidence of 75 per cent. infection, diagnosis by vermifuge revealed an incidence of 97 to 100 per cent. The usual method of diagnosis of hookworm infection by microscopic examination of stools for ova does not convey a quantitative idea of the severity of the infection-i.e., the number of worms harboured by an individual-and the degree of injury wrought on the patient. The grade of infection existing runs from 1 to a thousand or more worms. In some villages the average is $40-50$ or less; in others 100-150 or more; different villages and special groups of people present infections of different grades of severity.

Diagnosis by means of vermifuge disclosed another fact of extreme importance-namely, that many persons are harbouring a large number of worms, and, consequently are suffering unconsciously from a severe drain in proportion to the number of worms harboured. Thus, a notion was derived not only that oftentimes a higher degree of infection existed than was suspected, but a working knowledge of the number of worms actually being harboured (frequently large) by the people of a locality was obtained. In campaign work it is important to ascertain the number of worms being harboured, for it is more desirable to institute campaigns for treatment in communities where the infections are heavy than where they are light.

The therapeutics of several vermicides, more particularly chenopodium, were investigated by a method in which the efficiency of the drug is expressed by the percentage number of worms a given dosage is able to. remove out of the total number harboured. The vermicides could thus be compared one with another according to the actual number of worms removed-the percentage of total worms removed. This affords a more directand trustworthy index of the efficiency of a vermicide than microscopic examinations of fæces for ova. Chenopodium was found to be more effective than thymol in killing hookworms, and it was even more efficacious in expelling ascaris and other helminths such as oxyuris, trichiuris, and tre matodes. Other things being equal, it is better to use the most efficacious drug.

Toxic symptoms are elicited with all vermicides in the higher dosages; it is therefore necessary to reduce the dose given to as small an amount as possible. Chenopodium retains its vermicidal efficiency upon reduction in dose better than thymol, and this is another reason for its employment. The Malaya Board ascertained that the dosage, $1.5 \mathrm{c.cm}$. oil of chenopodium, was highly efficient and but slightly toxic, sometimes causing transient dizziness and vomiting. Two treatments of this dosage removed 99 per cent. of the hook-

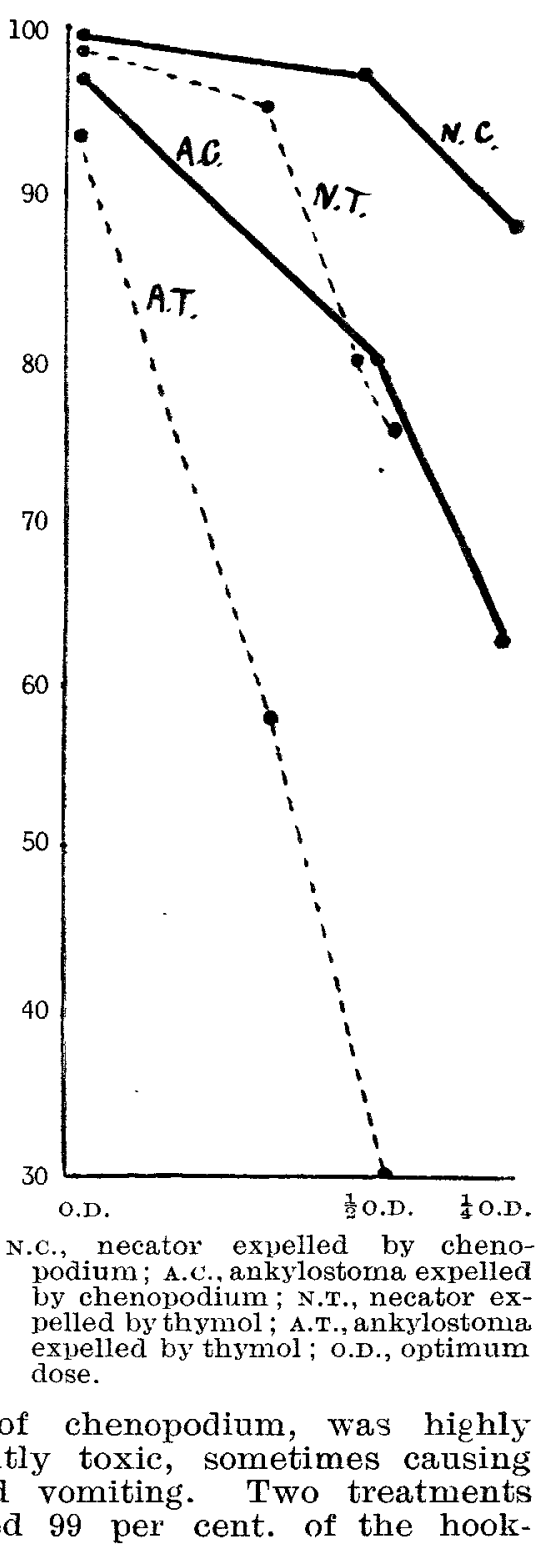

